\title{
VARIABILIDADE DA PRECIPITAÇÃO MENSAL E ANUAL NO MUNICÍPIO DE PARAGOMINAS-PA
}

Nathália Melo Giuliatti ; Ana Beatriz Matos Rodrigues; Edmir dos Santos Jesus², Antônio Pereira Junior ${ }^{3}$.

1Concluintes do curso de Engenharia Ambiental. Universidade do Estado do Pará.

2 Doutor em Ciências Atmosféricas. . Universidade do Estado do Pará.

3 Mestre em Ciências Ambientais. Universidade do Estado do Pará. Paragominas. Brasil.

E-mail: antonio.junior@uepa.br

Recebido em: 06/04/2019 - Aprovado em: 10/06/2019 - Publicado em: 30/06/2019

DOI: 10.18677/EnciBio_2019A133

\begin{abstract}
RESUMO
Atualmente a ocorrência de eventos relacionados ao clima como ondas de calor, precipitação extrema e inundações costeiras têm sido intensificadas por atividades antrópicas, que também são afetadas negativamente por esses fenômenos climáticos, dentre as quais pode-se citar a agricultura. Nesse sentido, é importante que seja realizada uma análise da precipitação pluviométrica em determinadas regiões. Assim, esta pesquisa teve como objetivo analisar quantitativa e qualitativamente a distribuição temporal das chuvas em Paragominas-PA e relacioná-la com a ocorrência dos fenômenos naturais denominados El Niño e La Niña. Para tanto, esta pesquisa possui abordagem quantitativa e qualitativa, natureza observativa e objetivo exploratório. A análise dos dados do período estudado indicou que há variabilidade pluviométrica no município tanto mensal quanto anualmente, de acordo com a qual, caracterizam-se como: chuvoso, os meses de dezembro a maio, e menos chuvoso (junho a novembro). Além disso, houveram diversas ocorrências de ambos, com forte intensidade. A pluviosidade mínima registrada no município dentro do período estudado foi de $1096 \mathrm{~mm}$ (1992) e a máxima de 2716,27 mm (2009).
\end{abstract}

PALAVRAS-CHAVE: Distribuição temporal. El Niño. La Niña.

\section{MONTHLY AND ANNUAL VARIABILITY OF PRECIPITATION IN THE CITY OF PARAGOMINAS - PA}

\begin{abstract}
Currently the occurrence of events related to the climate such as heat waves, extreme precipitation and coastal flooding have been intensified by anthropic activities, which are also negatively affected by these climatic phenomena, among which we can cite agriculture. In this sense, it is important to carry out an analysis of rainfall in certain regions. Thus, this research aims to quantitatively and qualitatively analyze the temporal distribution of rainfall in Paragominas-PA and to relate it to the occurrence of natural phenomena called El Niño and La Niña. Therefore, this
\end{abstract}


research has a quantitative and qualitative approach, observational nature and exploratory objective. The analysis of the data indicated that there is pluviometric variability in the municipality both monthly and annually, according to which, are characterized as: rainy, the months of December to May, and dry, June to November. In addition, there were several occurrences of both, with strong intensity. The minimum rainfall recorded in the municipality during the studied period was $1096 \mathrm{~mm}$ (1992) and the maximum rainfall was $2716.27 \mathrm{~mm}$ (2009).

KEYWORDS: Temporal distribution. El Niño. La Niña.

\section{INTRODUÇÃO}

O clima da Terra sempre esteve sujeito a mudanças moduladas por ciclos longos ou curtos, registrados na história da humanidade. Neste viés, o território brasileiro é marcado por relevante característica, que se denomina tropicalidade e é o predomínio de um clima com altas temperaturas e altos índices pluviométricos que ocorrem especialmente no verão. Além disso, a atuação de outros fatores climáticos também influencia de maneira significativa as variações locais e regionais desencadeando diferenças de um lugar para outro (PAULA et al., 2010; TORRES; MACHADO, 2011).

A atmosfera caracteriza-se por sua complexidade. Sob esta perspectiva, a climatologia é um dos ramos da Geografia Física que estuda os caracteres da atmosfera em contato com a superfície terrestre. Entretanto, em função da natureza dos elementos que analisa, a climatologia encontra fundamentos na meteorologia, que estuda a atmosfera e seus fenômenos, e preocupa-se com o registro e a medição destes de modo a determinar as condições físicas sob as quais foram produzidos (BARROS; ZAVATTINI, 2009).

Nesse sentido, a distribuição das chuvas no espaço e no tempo é de fundamental importância para gerenciamento dos recursos naturais, por isso, a precipitação pluvial tem sido estudada em diferentes regiões do mundo, em face de sua importância no ciclo hidrológico e a manutenção dos seres vivos no planeta. A previsão da distribuição espacial e temporal das chuvas baseada em séries históricas fornece dados consistentes para pesquisas como a estimativa de perda de solo, análises Agrometeorológicas e planejamento urbano (MEUSBURGER et al., 2012; WILLEMS et al., 2012;).

Não obstante, para que haja uma análise da precipitação pluviométrica em determinada região, é necessário o conhecimento sobre as chuvas dessa localidade. As zonas de maior pluviosidade, por exemplo, coincidem com as áreas de convergência do ar. As estimativas estão intrinsecamente ligadas à disponibilidade de dados de precipitação e a qualidade destes, bem como sua distribuição espacial. Com isso, a utilização de estações meteorológicas é imprescindível, pois, são equipamentos de monitoramento e registro de condições climáticas com sensores configuráveis para análise de parâmetros atmosféricos como a pressão atmosférica, temperatura e umidade relativa do ar, precipitação, radiação solar, direção e velocidade do vento (COSTA et al., 2012).

Ademais, as principais diferenças das características climáticas médias entre as estações de verão e inverno correspondem ao posicionamento e intensidade do jato subtropical de altos níveis em cada um dos hemisférios e, na faixa tropical, ao deslocamento meridional da célula de Hadley, da convecção local e da Zona de Convergência Intertropical (ZCIT). No hemisfério sul, durante o verão, as áreas de convecção e a ZCIT são deslocadas para o sul, retornando para o norte durante o ENCICLOPÉDIA BIOSFERA, Centro Científico Conhecer - Goiânia, v.16 n.29; p. 1717 2019 
inverno. Devido à maior variação meridional de temperatura durante o inverno, nos dois hemisférios, o jato fica mais intenso e mais abrangente nesta época do ano (SILVA et al., 2011; LOPES et al., 2013; LIMBERGER; SILVA, 2016).

No que tange à precipitação pluvial da região amazônica, esta se destaca, pois sofre influência de mudanças climáticas globais. Por meio dos dados contidos em estações meteorológicas, foi possível relacionar a falta de chuvas à ocorrência do El Niño, e o excesso, principalmente, em anos com ocorrência de La Niña. Esses dois fenômenos estão relacionados ao aquecimento ou esfriamento anormal das águas de superfície do Oceano Pacífico na região dos trópicos. Tal fato, afeta o regime de chuvas na região amazônica e em outras partes do mundo e ocasionam a alteração significativa da vazão dos rios, sendo frequentemente muito prejudiciais para o ritmo de vida da população (HIGUCHI et al., 2011; REBOITA; SANTOS, 2014).

Apesar de saber que a precipitação é caracterizada de acordo com os principais centros de ação moduladores do clima de determinado lugar, apenas uma fração da variabilidade da precipitação na Amazônia pode ser explicada pelo El Niño Oscilação Sul (ENOS), e esta relação é mais atuante somente durante a estação chuvosa. Isso deve-se ao fato de que a variabilidade interanual de precipitação nas regiões Norte e Nordeste da América do Sul devem também considerar as variações interanuais da Temperatura da Superfície do Mar (TSM) associadas ao fenômeno ENOS e às que ocorrem no Atlântico Tropical - AT (ARAÚJO et al., 2013; JACOX et al., 2016).

Dentre os principais prejuízos que tais eventos climatológicos podem acarretar, na região Amazônica, pode-se citar o aumento da incidência de doenças e a dificuldade de acesso e remanejamento das famílias em casos de enchentes. Além desses, há registros de prejuízos em atividades antrópicas, como pesca, agricultura de subsistência, transporte e escoamento da produção e distribuição de água potável. Especialmente nas áreas urbanas, verificam-se danos na infraestrutura, tais como em redes de água, esgoto e vias de acesso. Em períodos de seca extrema, verifica-se o aumento da mortandade de peixes, já que os lagos secam ou ficam com pouca água, o que aumenta a demanda por oxigênio (BORMA et al., 2013).

Conforme os relatórios do Painel Intergovernamental sobre Mudanças Climáticas (IPCC, 2014), eventos relacionados ao clima como ondas de calor, precipitação extrema e inundações costeiras são reflexos de atividades antrópicas (urbanização desenfreada e desmatamento). Quanto ao meio urbano, os assentamentos em locais mais sujeitos à ação destrutiva são os mais vulneráveis a enchentes, aos deslizamentos e enxurradas. Isso ocorre porque os impactos ambientais associados às condições ambientais físicas têm influência direta na definição das vulnerabilidades ambientais a que os geoambientes estão suscetíveis.

Nas últimas décadas, desastres decorrentes de eventos naturais atingiram todo o país. No ano de 2011, o Serviço Geológico do Brasil (CPRM), passou a integrar o Plano Nacional de Gestão de Riscos e Resposta aos Desastres Naturais (PNGRRDN), no qual, dentre as metas estipuladas, objetivou-se mapear 821 municípios prioritários. O objetivo foi atingido em 2014, mas o CPRM deu continuidade aos trabalhos de setorização de riscos geológicos. Com isso, em 2018 foi realizado o mapeamento de risco de Paragominas - PA, após o município ter sofrido a ocorrência de uma enxurrada impulsionada por fatores hidrológicos e antrópicos (FONSECA; MIYAGAWA, 2018). 
Desse modo, a análise da tendência de séries históricas de precipitação é uma das maneiras de determinar a ocorrência de mudança climática local, possibilitando a avaliação de suas consequências sob (sobre) o meio ambiente e a população. Assim, a relevância desta pesquisa constitui-se da importância de conhecer os aspectos hidrometeorológicos que influenciam nas variações climáticas e como a ação humana pode contribuir para possíveis alterações no clima local. Em vista disso, objetivo desta pesquisa o objetivo dessa pesquisa foi analisar quantiqualitativamente a distribuição temporal das chuvas em Paragominas - PA e relacioná-la com a ocorrência dos fenômenos El Niño e La Niña.

\section{MATERIAL E MÉTODOS ÁREA DE ESTUDO}

$A$ área de estudo é o município de Paragominas (Figura 1), localizado às margens da BR 010 (Belém-Brasília), que, de acordo com Andrade (2011), integra a mesorregião sudeste do estado do Pará, e possui área de 19.330 quilômetros quadrados.
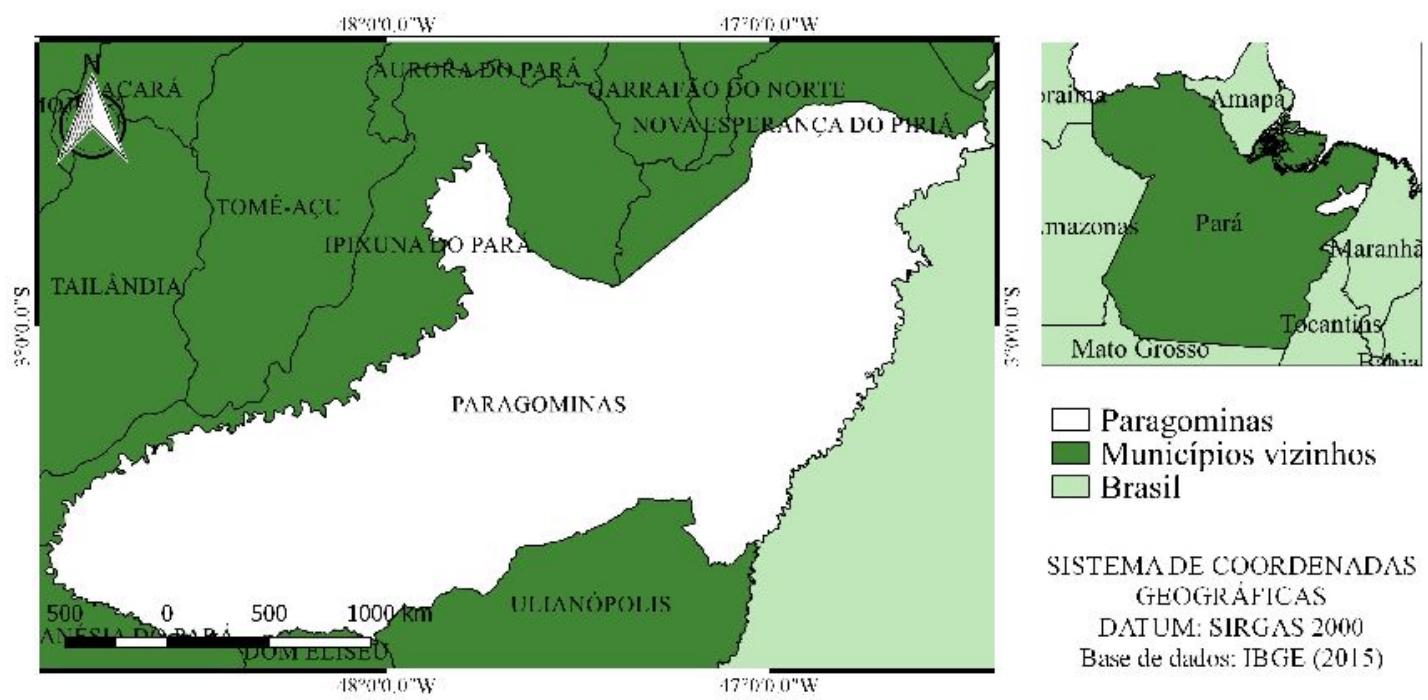

FIGURA 1 - Mapa político e geográfico da localização do município de ParagominasPA. Fonte: autores (2018).

Segundo Pinto et al. (2009), o clima do município é do tipo quente e úmido com temperatura média anual de $26^{\circ} \mathrm{C}$ e umidade relativa do ar, média igual a $81 \%$. O período mais chuvoso é compreendido entre dezembro e maio e outro mais seco entre junho e novembro. Possui população estimada pelo IBGE (2018) em 110.026 habitantes.

O município de Paragominas é um polo tradicional de uma grande região, na qual as principais atividades são rurais, sendo a pecuária, com cerca de 490.000 ha de pastagens, e a agricultura. Os solos em que predomina a agricultura pertencem ao grande grupo Latossolo Amarelo, com alto teor de argila (acima de $70 \%$ ). Normalmente, os solos são de baixa fertilidade natural, porém com boas características físicas (ALVES et al., 2014). 


\section{MÉTODO}

O método aplicado foi o dedutivo, pois este trata-se de um processo por meio do qual parte-se uma verdade geral ou universal (variabilidade das taxas pluviométricas e a relação destas com fenômenos meteorológicos), e se deduz fatos particulares (comportamento pluviométrico no município de Paragominas-PA e a ocorrência de El Niño e La Niña). Portanto, o objetivo inferência dedutiva é levar a conclusões cujo conteúdo é mais reduzido do que as premissas nas quais foi baseado (PRODANOV; FREITAS, 2013). Quanto à pesquisa, de acordo com o exposto por Sakamoto e Silveira (2014), é de natureza observativa, com abordagem quantiqualitativa e objetivo exploratório

A técnica aplicada para a obtenção de dados foi o levantamento de dados documentais em sites de livre acesso: Instituto Brasileiro de Geografia e Estatística (IBGE), Instituto Nacional de Pesquisas Espaciais (INPE) e Instituto Nacional do Semiárido (INSA) e buscadores como Scientific Eletronic Library Online (SciELO), Google Scholar e Coordenação de Aperfeiçoamento de Pessoal de Nível Superior (CAPES). Os descritores utilizados foram: (1) taxas pluviométricas em ParagominasPA de 1989 a 2018; e (2) ocorrência de El Niño e La Niña de 1989 a 2018.

\section{COLETA DE DADOS PLUVIOMÉTRICOS E TRATAMENTO ESTATÍSTICO}

Os dados pluviométricos foram coletados na plataforma digital HidroWeb, da Agência Nacional de Águas (ANA). Foram analisadas as estações pluviométricas do município quanto à maior proximidade com a área urbana, à série temporal de dados disponíveis e à quantidade de falhas nessas séries. A estação selecionada foi a de Paragominas e identificada pelo código 00347000 (www.hidroweb.ana.gov.br), com coordenadas geográficas de $03^{\circ} 00^{\prime} 36^{\prime \prime} \mathrm{S}$ e $47^{\circ} 20^{\prime} 36^{\prime \prime} \mathrm{W}$ (Figura 2).

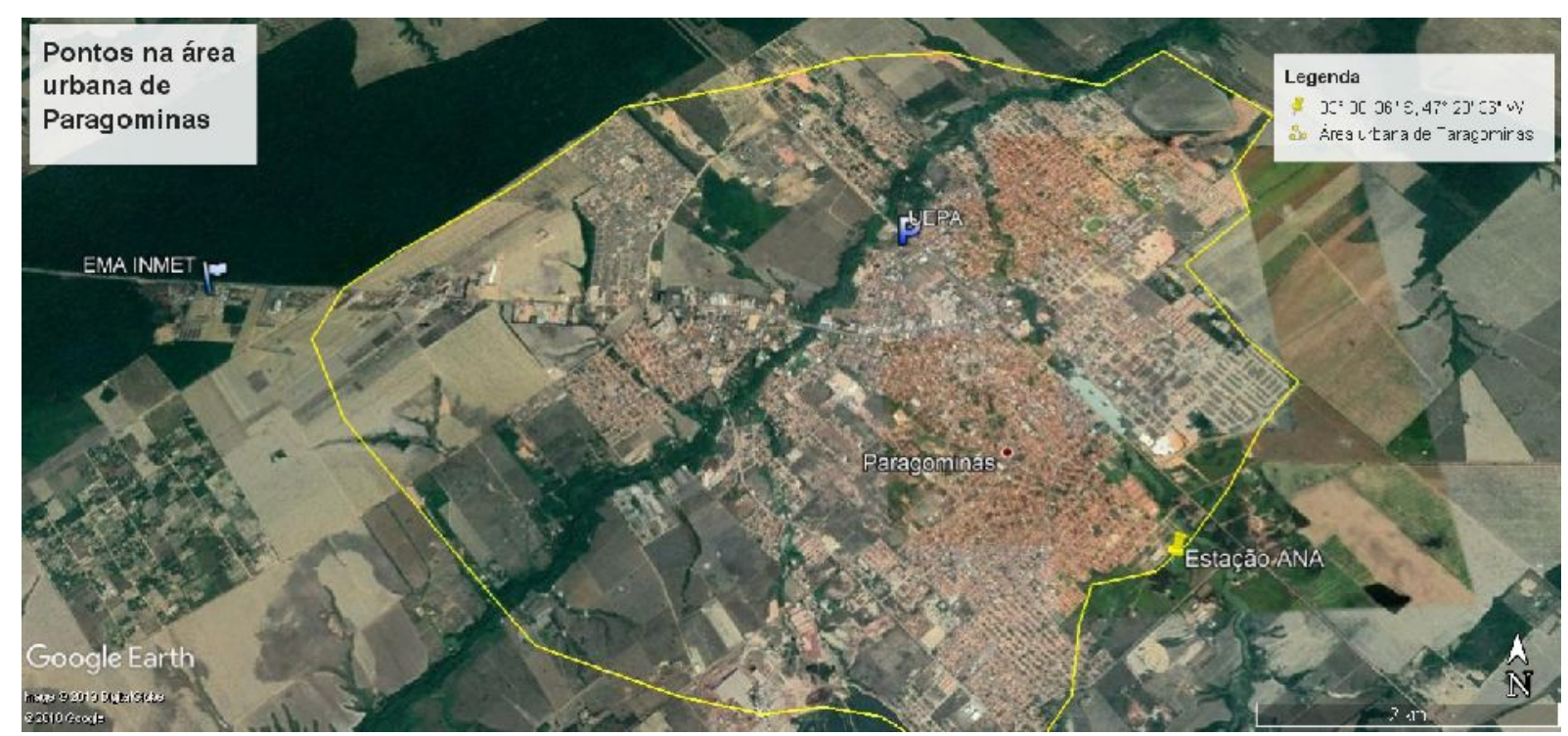

FIGURA 2 - Localização da estação pluviométrica selecionada para coleta de dados. Paragominas - PA.

Fonte: autores (2018).

Essa estação foi selecionada devido ao baixo número de falhas e à posição, pois está localizada a cerca de 300 metros da margem esquerda do rio Paragominas, que tem cerca de $4,5 \mathrm{~km}(27,2 \%)$ do curso inseridos na zona urbana. Esta possui uma uma série histórica de 38 anos (1981 a 2018), da qual foram 
utilizados os dados referentes a 30 anos (1989 a 2018) para análise das taxas pluviométricas no município. Totalizando assim 352 meses, de janeiro de 1989 a abril de 2018, e continha falhas em 20 meses.

As falhas identificadas foram preenchidas por meio do método de regressão linear simples (NASCIMENTO et al., 2009). Para tanto, foram identificadas outras duas estações (Cafezal e Rio Capim) próximas à estação Paragominas e com poucas falhas de preenchimento. Em seguida, foram calculados os coeficientes de ajustamento $\left(R^{2}\right)$ entre a estação Paragominas e essas duas estações para identificação do ajustamento linear entre as séries temporais. $O R^{2}$ foi superior para a relação entre a estação Paragominas e a Rio Capim $(0,7437)$ em comparação à Cafezal $(0,7082)$.

Dessa forma, o preenchimento das falhas da estação Paragominas, foi realizado a partir da equação obtida pelo cálculo de regressão linear entre as estações Paragominas e Rio Capim (código 00247006), sendo $y=0,9368 x+37,091$, na qual o $x$ equivale ao total mensal das taxas pluviométricas na estação Rio Capim e o y à falha a ser preenchida. Com isso, foram plotados, no software Microsoft Excel 2010, quatro gráficos demonstrativos dos índices pluviométricos a) anuais; b) mensais; c) dos dois meses mais chuvosos e dois meses mais secos; e d) da ocorrência dos fenômenos El Niño e La Niña com base nas taxas anuais.

Os dados pluviométricos obtidos foram tratados estatisticamente com o uso do software BioEstat 5.3 (AYRES et al., 2007), no qual foi empregada a estatística descritiva. Foram calculados: a) a média, utilizada para análise geral das taxas pluviométricas anuais e mensais em Paragominas-PA; b) o coeficiente de variação, para expressar a variação percentual dos valores em relação à média; e c) os valores de pluviosidade máximos e mínimos contidos na série temporal estudada (BITTENCOURT, 2014).

\section{RESULTADOS E DISCUSSÃO \\ VARIAÇÃO ANUAL DA PRECIPITAÇÃO}

Os valores de precipitação anual, registrados durante o período de 1989 a 2018, no município de Paragominas sofrem variações com mínima de $1.096 \mathrm{~mm}$ e máxima de 2.716,27 mm, as quais ocorreram nos anos de 1992 e 2009, respectivamente (Figura 3).

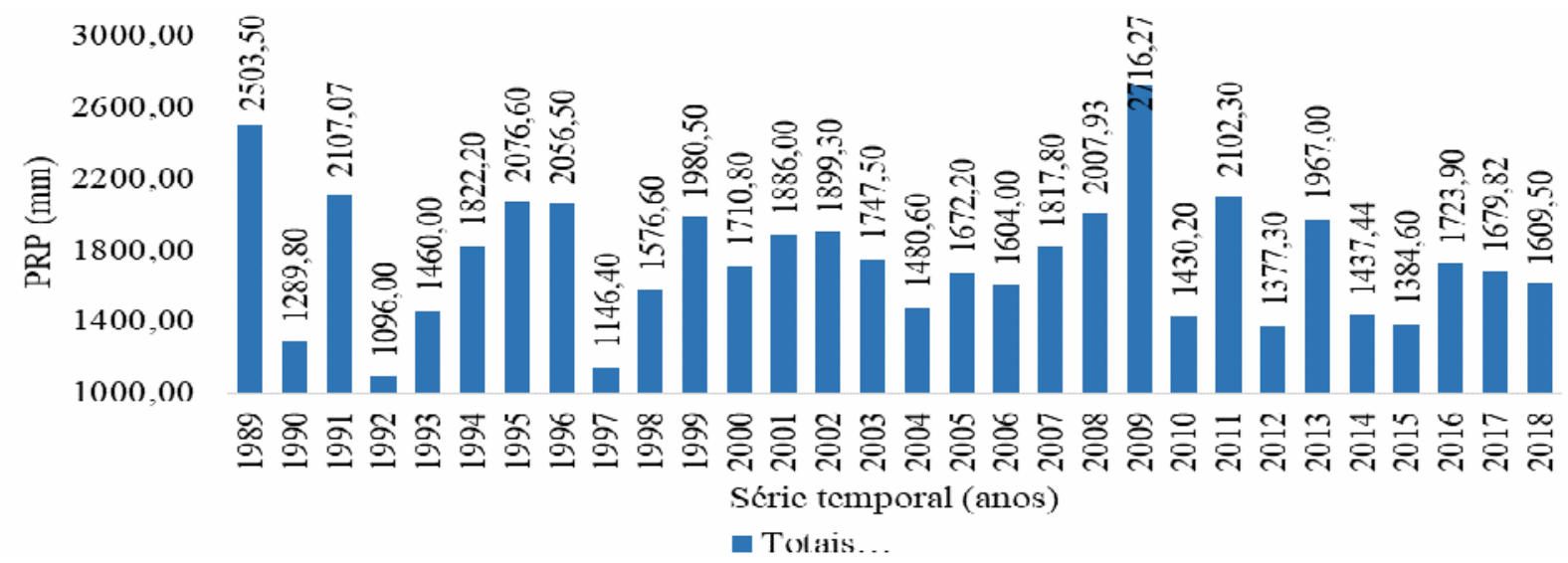

FIGURA 3 - Valores para as taxas pluviométricas anuais no município de Paragominas - PA, registradas durante a série temporal de 1989 a 2018.

Fonte: autores (2018) 
A análise dos dados obtidos indicou que a pluviosidade média ocorrida no município, de 1989 a 2018, foi de $1745.65 \mathrm{~mm}$ anuais, com coeficiente de variação de $20,97 \%$ em relação à média. Dessa forma, o período chuvoso do município pode ser caracterizado como de altos valores pluviométricos e com um grande número de dias de chuva. Segundo pesquisas realizadas por Silva et al. (2011) e Silva et al. (2012), ambas na região Nordeste do Brasil, essas características decorrem da relação entre o coeficiente de variação e o comportamento meteorológico, uma vez que maiores valores de coeficiente de variação estão associados a menores valores de precipitação pluvial e de número de dias de chuva e vice-versa.

A taxa pluviométrica anual de $1609.5 \mathrm{~mm}$ registrada em 2018 refere-se somente à soma da precipitação pluvial ocorrida nos meses de janeiro a abril, devido aos dados disponíveis, mas ainda assim supera o total anual (12 meses) de 1596.8 $\mathrm{mm}$ registrado em 2017, o que demonstra os altos índices de chuva no início de 2018.

\section{VARIAÇÃO MENSAL DA PRECIPITAÇÃO}

As taxas pluviométricas mensais variam de acordo com o período do ano. As maiores taxas, durante os anos 1989 a 2018, foram registradas nos meses de março, com média de $357.1 \mathrm{~mm}$ e as menores taxas são aquelas referente aos meses de setembro, com média de $19.0 \mathrm{~mm}$ (Figura 4).

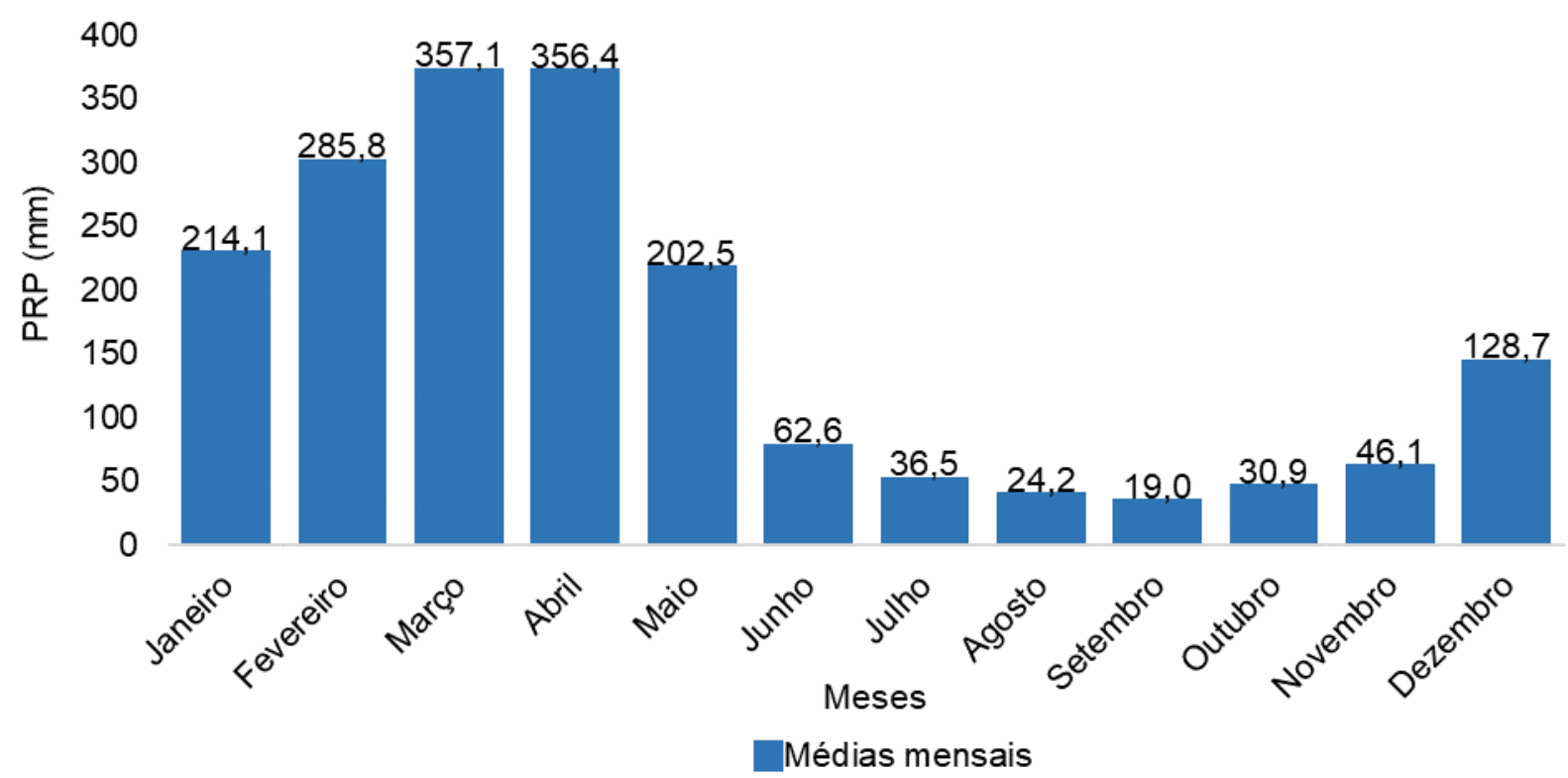

FIGURA 4 - Valores para as taxas pluviométricas mensais médias registradas no município de Paragominas-PA durante a série temporal de 1989 a 2018.

Fonte: autores (2018).

A análise dos dados obtidos indicou que o período no qual as taxas pluviométricas são mais altas está compreendido de dezembro a maio, enquanto o período de menores taxas refere-se aos meses de junho a novembro. Devido a tal comportamento climatológico, estudo efetuado por Pinto et al. (2009), em Paragominas - PA, concluiu que estes períodos se referem, respectivamente, aos períodos chuvoso e seco no município, o que Lopes et al. (2013) caracterizam como inverno e verão amazônicos. 
No período chuvoso, os meses nos quais as taxas pluviométricas são mais altas são março e abril, respectivamente, com variação da taxa média de apenas 0,7 $\mathrm{mm}$ entre eles, enquanto os meses com taxas mais baixas são agosto e setembro, com variação de 5,2 $\mathrm{mm}$ (Figura 5).

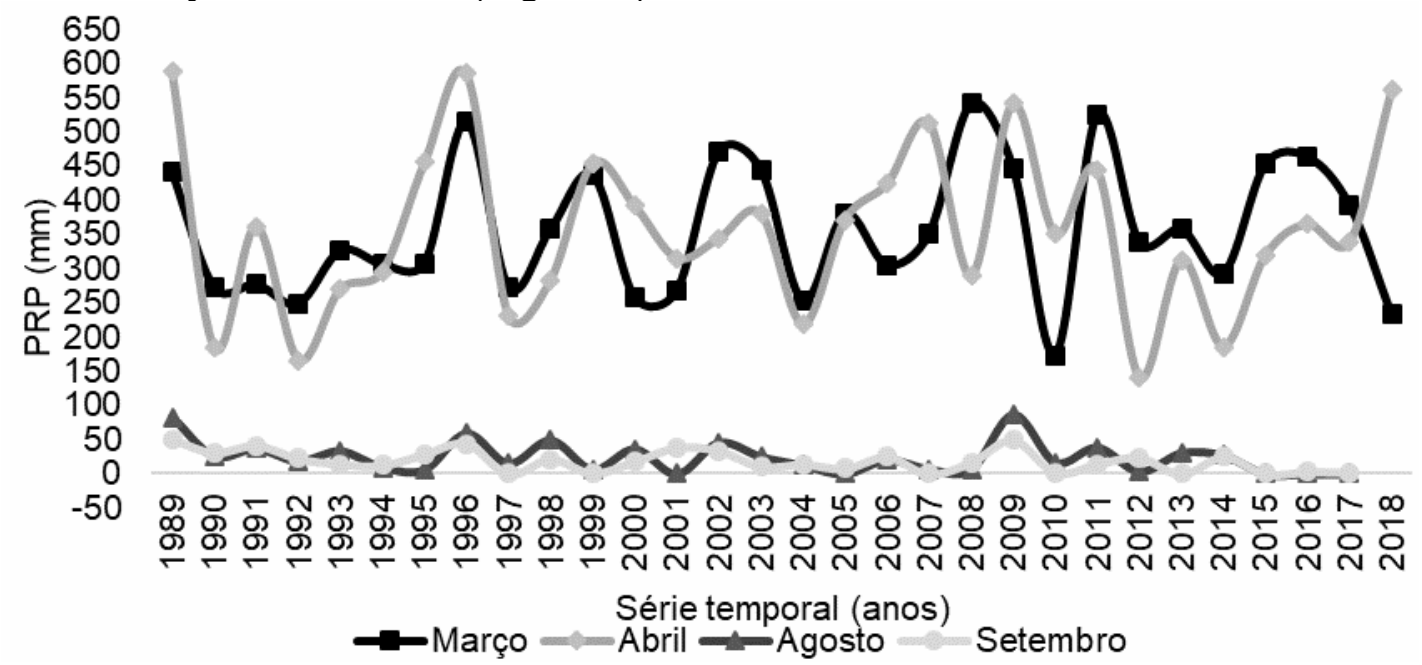

FIGURA 5 - Valores para as taxas pluviométricas nos meses de março, abril, agosto e setembro registradas no município de Paragominas-PA durante a série temporal de 1989 a 2018.

Fonte: autores (2018).

A partir da análise dos dados, constatou-se que os meses de março e abril apresentaram os maiores índices pluviométricos durante a série temporal estudada, sendo março o mês mais chuvoso em $13(43.33 \%)$ dos 30 anos estudados e abril o mais chuvoso em sete anos (23,33\%). As pluviosidades máximas dos 10 anos restantes foram registradas em fevereiro $(20 \%)$, maio $(10 \%)$ e janeiro $(3,34 \%)$. Os coeficientes de variação das taxas de março e abril são, respectivamente, de $27,33 \%$ e $34,76 \%$, ou seja, não houve linearidade nos valores de precipitação pluvial, ainda que estes estivessem entre os mais altos durante o período de estudo. Tais resultados são confirmados por estudo efetuado por Andrade (2011), em Paragominas - PA, contudo, o autor identificou o mês de maio, como o mais seco.

Quanto aos meses do verão amazônico, os dados obtidos indicaram que os meses de menor pluviosidade média foram agosto e setembro. No entanto, os meses com maior recorrência de registro anual de pluviosidade mais baixa foram: outubro, em nove dos 30 anos (30\%), e agosto, em oito dos 30 anos (26.67\%), seguidos por setembro em sete dos 30 anos estudados (23.33\%). Nos seis anos restantes foram registradas as menores taxas pluviométricas em novembro $(10 \%)$ e julho $(6.67 \%)$. Devido à indisponibilidade de dados referentes ao período de maio a dezembro de 2018 nas estações do município, o mês com menor pluviosidade registrada foi março, com $232,7 \mathrm{~mm}$, pois está contido no período chuvoso do município.

TAXAS PLUVIOMÉTRICAS ANUAIS E A OCORRÊNCIA DE EL NIÑO E LA NIÑA

As variabilidades mensal e consequentemente a anual das taxas pluviométricas no município sofre influência de fenômenos climáticos, como o El Niño e o La Niña (Figura 6). 


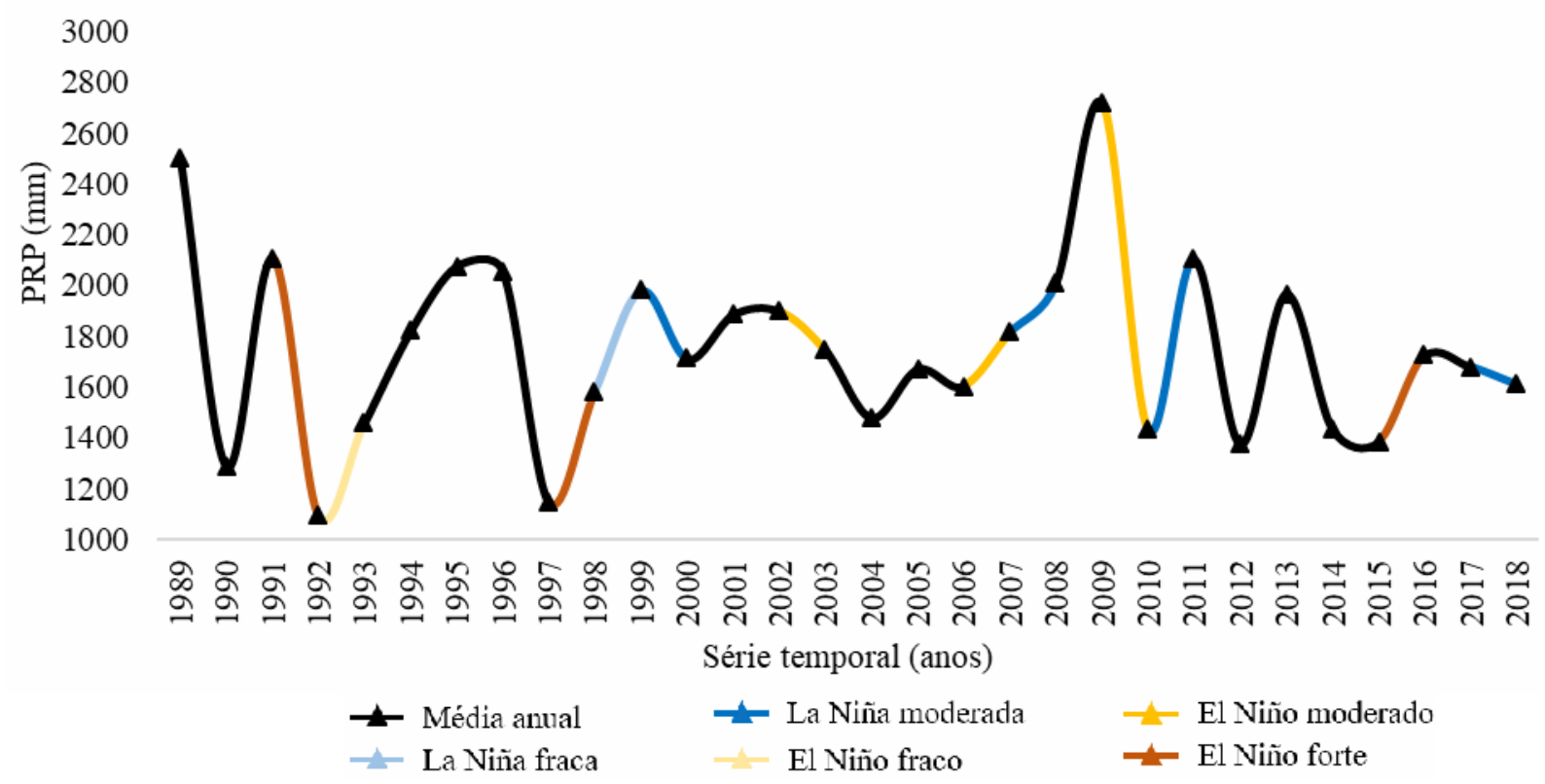

FIGURA 6 - Demonstrativo das taxas pluviométricas anuais registradas no município de Paragominas-PA durante a série temporal de 1989 a 2018 e da ocorrência de El Niño e La Niña no mesmo período.

Fonte: elaborado a partir de dados coletados no INPE (2018).

A análise dos dados indicou que durante o período estudado, houve ocorrência de El Niño sete vezes e de La Niña cinco vezes, o que teve influência sobre os índices de chuva em toda a região amazônica, bem como no município. Pesquisa efetuada por Reboita e Santos (2018), nas regiões Norte e Nordeste do Brasil, indica que o fenômeno La Niña intensifica a atividade convectiva na Amazônia, o que favorece o aumento da precipitação pluvial na região, enquanto El Niño reduz a atividade convectiva e, consequentemente, os índices de chuva sofrem redução. Os autores denominam os demais anos, nos quais não houve ocorrência de nenhum dos fenômenos citados, como anos normais ou neutros.

O Instituto Nacional de Pesquisas Espaciais (INPE, 2018), indica o acontecimento desses fenômenos como interanual, pois, conforme estudo efetuado por Paula et al. (2010), em Santa Maria - RS, a duração deles é variável e pode ser de cinco a 15 meses, dependendo dos graus de aquecimento ou resfriamento das águas do Oceano Pacífico. Nesse sentido, as variações na pluviosidade decorrente do El Niño foram percebidas nos períodos de 1991/1992, 1992/1993, 1997/1998, 2002/2003, 2006/2007, 2009/2010 e 2015/2016, com três variações negativas e quatro variações positivas. As variações na pluviosidade decorrentes do La Niña foram identificas nos períodos de 1998/1999, 1999/2000, 2007/2008, 2010/2011 e 2017/2018. As variações dependem da intensidade do fenômeno climático e se este ocorre simultaneamente a outros.

No ano de 1992, foi registrada a menor precipitação pluvial (PRP) da série temporal, pois todo o ano estava sob ação do El Niño, uma vez que de 1991 a um primeiro momento de 1992 o fenômeno teve ocorrência forte e, em seguida, do final do ano de 1992 a 1993, teve ocorrência moderada. No período de 1997 a 1998, a intensidade do El Niño também foi forte, contudo, a variação das taxas pluviométricas foi positiva, ainda que a pluviosidade anual em 1998 tenha sido 
abaixo da média anual. O ano de 1997 apresentou a segunda menor taxa da série temporal.

Isso pode estar relacionado à ocorrência do fenômeno de modo mais intenso ter sido predominantemente em 1997, pois, Paula et al. (2010) indicam que nesse período, o fenômeno teve duração de 12 meses, enquanto Berlato e Fontana (2011) complementam que o El Niño teve início em julho de 1997, e fim no mês de junho de 1998. A análise dos dados obtidos a partir da estação pluviométrica em Paragominas-PA indica que as menores taxas são aquelas referente aos meses de julho a dezembro de 1997, com média de $25.7 \mathrm{~mm}$, o que corresponde a apenas 43.69\% da precipitação registrada no mesmo período do ano de 1998 (58.8 mm).

Em seguida à ocorrência do El Niño, houveram dois períodos de La Niña (1998/1999 e 1999/2000), com um acréscimo e um decréscimo, respectivamente, da pluviosidade no município de Paragominas - PA. Dessa forma, percebeu-se maior pluviosidade no ano de 1999 em relação aos outros dois, pois todos os meses de 1999 estavam sob ação do aumento das taxas pluviométricas ocasionado por aquele fenômeno natural.

No período de 2002 a 2003, o El Niño teve ocorrência moderada, com pequena redução da média anual de pluviosidade de $2003(1747,5 \mathrm{~mm})$ em relação ao ano anterior (1899.30 mm). Os períodos de 2006/2007 e 2007/2008 sofreram influência do El Niño e do La Niña, respectivamente, como aumento da pluviosidade em ambos. Paula et al. (2010), em pesquisa realizada em Santa Maria - RS, indicaram que o El Niño ocorrido nesse período foi moderado e teve duração de apenas seis meses, o que, consequentemente, pode ter resultado apenas em uma baixa interferência na pluviosidade desse período. Assim, foi identificada variação positiva das taxas pluviométricas e não negativa, como geralmente ocorre.

Em 2008/2009, apesar de não ter havido nenhum dos dois fenômenos meteorológicos citados, o acumulado de chuvas no ano foi alto, de modo que no ano de 2009 foi registrada a maior pluviosidade anual $(2716.3 \mathrm{~mm})$. Posteriormente ao acréscimo das taxas pluviométricas, 2009/2010 foram anos de El Niño moderado, com a maior variação negativa $(1286.1 \mathrm{~mm})$, seguida de uma variação positiva em anos de La Niña (2010/2011). Em 2011, foi registrada a terceira maior PRP (2102.3 $\mathrm{mm}$ ) da série temporal.

Pesquisa realizada por Kim et al. (2011), caracterizou esse período como o de mais rápida fase de transição do aquecimento para o resfriamento das águas do Oceano Pacífico, o que pode ser justificado, dentre outros, devido ao El Niño ter sido acompanhado por uma forte propagação anômala de frio nas águas subsuperficiais em direção ao leste do continente americano.

No período de 2015/2016 ocorreu o terceiro El Niño de forte intensidade contido na série temporal. Em pesquisa realizada por Levine e McPhaden (2016), eles indicam que o fator determinante para que o fenômeno fosse caracterizado como forte, foi o anômalo volume remanescente de água quente gerado durante o verão de 2014, que permaneceu aquecido mesmo durante o inverno de 2014/2015 dando início ao fortalecimento do El Niño em 2015/2016. Contudo, a variação das taxas pluviométricas no município de Paragominas - PA foi positiva no ano de 2016 em relação ao ano anterior.

De acordo com pesquisa realizada por Jacox et al. (2016), na Califórnia, isso pode ter ocorrido porque, apesar de a temperatura da superfície oceânica do Pacífico ter atingido níveis recordes no final de 2015 , estas não foram 
acompanhadas por forte geração equatorial de ondas Kelvin (ondas suaves de água morna), o que enfraqueceu o fenômeno no fim da ocorrência em 2016.

A última ocorrência desses fenômenos foi em 2017/2018, com La Niña de intensidade moderada. Isso pode ser percebido no índice de chuvas do ano de 2018, pois, como indicado anteriormente, a pluviosidade anual de $1609.5 \mathrm{~mm}$ registrada para o ano de 2018 refere-se somente à soma da precipitação pluvial ocorrida nos meses de janeiro a abril e, ainda assim, equipara-se ao total anual (12 meses) de 2017 (1679.8 mm).

A alta PRP nesse período afetou o município negativamente. De acordo com relatório produzido por Fonseca e Miyagawa (2018) acerca das áreas que apresentam risco a enchentes e inundações, houve precipitação de cerca de 110 $\mathrm{mm}$ em apenas uma hora, no dia 11 de abril de 2018. Tal acontecimento ocasionou grandes inundações, associadas também ao rompimento de três barragens localizadas em imóveis rurais à montante dos rios Uraim e Paragominas. As precipitações nos meses de fevereiro e abril de 2018 foram de $581.1 \mathrm{~mm}$ e 561.7 $\mathrm{mm}$, respectivamente, o que excede a pluviosidade desses meses, que apresentam taxas médias de $285.5 \mathrm{~mm}$ e $356.4 \mathrm{~mm}$

A ocorrência desses fenômenos meteorológicos tem influência sobre diversas atividades econômicas, dentre as quais a agricultura é uma das mais afetadas, seja pela falta ou excesso de chuvas. Pesquisa realizada por Marengo et al. (2011), no Nordeste do Brasil, indicou que, durante o El Niño de 1998, por exemplo, a seca foi intensa nessa região, devido aos cerca de $4^{\circ} \mathrm{C}$ de aquecimento da superfície oceânica, o que resultou na queda da produção agrícola da região. Quanto ao excesso de chuva, Borma et al. (2013) destacam a possibilidade de inundações, as quais são resultados de grandes volumes de chuva que não foram devidamente direcionados aos rios e infiltrados no solo devido à impermeabilização do solo das cidades.

\section{CONCLUSÃO}

Os meses que apresentaram maiores taxas pluviométricas foram aqueles compreendidos de dezembro a maio (inverno amazônico), enquanto os de menor precipitação pluviométrica estão entre junho e novembro (verão amazônico). Desses, o mês mais chuvoso foi março e o mais seco foi setembro. Quanto às taxas anuais, o ano de mais baixa PRP foi 1992 e o de mais alta foi 2009, pois, dentre outros fatores, estavam inseridos em períodos de ocorrência de El Niño e La Niña, respectivamente.

Este estudo contribui para a compreensão do comportamento da pluviosidade no município de Paragominas quando exposta a fenômenos climáticos, o que contribui para um melhor planejamento urbano e rural das atividades antrópicas. Logo, permitem que sejam implementadas medidas mitigadoras de danos, como a irrigação, em casos de seca, ou o aprimoramento das redes de drenagem pluvial, em ocasião de excesso de chuvas.

\section{REFERÊNCIAS}

ALVES, L. W. R.; CARVALHO, E. J. M.; SILVA, L. G. T. Diagnóstico agrícola do município de Paragominas, PA. Boletim de Pesquisa e Desenvolvimento (INFOTECA-E), Belém: Embrapa Amazônia Oriental, p. 26, 2014. Disponível em: https://www.infoteca.cnptia.embrapa.br/infoteca/bitstream/doc/988380/1/BPD91.pdf. ISSN: 1983-0483. Acesso em 23 dez. 2018. 
ANDRADE, F. S. Variabilidade da precipitação pluviométrica de um município do estado do Pará. Revista de Engenharia Ambiental, Espírito Santo do Pinhal, v. 8, n. 4, p. 138-145, out./dez. 2011. Disponível em: http://ferramentas.unipinhal.edu.br/engenhariaambiental/viewarticle.php?id=632\&lay out=abstract. ISSN: 1809-0664. Acesso em 22 dez. 2018.

ARAÚJO, R. G.; ANDREOLI, R. V.; CANDIDO, L. A.; KAYANO, M. T.; SOUZA, R. A. F. A influência do evento El Niño-Oscilação Sul e Atlântico Equatorial na precipitação sobre as regiões norte e nordeste da América do Sul. Acta Amazônica, Manaus, v. 43, n. 4, p. 469-480, 2013. Disponível em: http://dx.doi.org/10.1590/S004459672013000400009. DOI: 10.1590/S0044-59672013000400009. Acesso em 22 dez. 2018.

AYRES, M.; AYRES JUNIOR, M.; AYRES, D. L.; SANTOS, A. S. Programa BioEstat 5.3. Aplicações Estatísticas nas Áreas das Ciências Biológicas e Biomédicas. Belém: Sociedade Civil Mamirauá, 2005.

BARROS, J.; ZAVATTINI, J. A. Bases conceituais em climatologia geográfica. Mercator-Revista de Geografia da UFC, v. 8, n. 16, p. 261, 2009. Disponível em: http://www.mercator.ufc.br/index.php/mercator/article/view/289. ISSN: 1984-2201. Acesso em 21 dez. 2018.

BERLATO, M. A.; FONTANA, D. C. El Niño e a agricultura da Região Sul do Brasil. $\quad 2011 . \quad$ Disponível em: http://www.cnpt.embrapa.br/pesquisa/agromet/agromet/elninolanina/elnino2.pdf.

Acesso 20 dez. 2018

BITTENCOURT, H. R. Estatística Aplicada à Engenharia. Rio Grande do Sul: PUC-RS, 2014.2 Disponível em: http://www.feng.pucrs.br/professores/helio/Especializacao_em_Engenharia_de_Proc essos_e_de_Sistemas_de_Producao/Estatistica/Material_Helio_FINAL_2014.pdf. Acesso em 22 dez. 2018.

BORMA, L. S.; TOMASELLA, S.T.; ROBALLO, L.A.; CUARTAS, D. A.; RODRIGUES, J. A. et al. Impactos dos eventos extremos de seca e cheia sobre os recursos hídricos amazônicos e ações da defesa civil. In: BORMA, L. S; NOBRE, C. A. Secas na Amazônia: causas e consequências. São Paulo: Oficina de Textos, 2013. p. 305-337.

COSTA, H. C.; MARCUZZO, F.; FERREIRA, O. M.; ANDRADE, L. R. Espacialização e Sazonalidade da Precipitação Pluviométrica do Estado de Goiás e Distrito Federal. Revista Brasileira de Geografia Física, v. 1, p.87-100, 2012. Disponível em: https://periodicos.ufpe.br/revistas/rbgfe/article/view/232785/26785. Acesso em 19 dez. 2018.

FONSECA, D. D. F.; MIYAGAWA, L. J. P. P. Setorização de Área em Alto e Muito Alto Risco a Movimentos de Massa, Enchentes e Inundações: Paragominas-PA. 
CPRM: 2018. Disponível em: http://rigeo.cprm.gov.br/jspui/handle/doc/20404. Acesso em 21 dez. 2018.

HIGUCHI, N.; SANTOS, J.; LIMA, A. J. N.; HIGUCHI, F. G.; CHAMBERS, J. Q. A floresta amazônica e a água da chuva. Floresta, v. 41, n. 3, p. 427-434, jul/set, 2011. Disponível em: https://revistas.ufpr.br/floresta/article/view/24060/16090. Acesso em 18 dez. 2018.

IBGE. Instituto Brasileiro de Geografia e Estatistica. Paragominas. Informações estatísticas. 2018. Disponível em: http://cidades.ibge.gov.br/xtras/perfil.php? lang=\&codmun=150550\&search=||infogr\%E1 ficos:-informa\%E7\%F5es-completas.

Acesso em 20 dez. 2018.

INPE. Instituto Nacional de pesquisas Espaciais. El Niño e La Niña. 2018. Disponível em: http://enos.cptec.inpe.br/. Acesso em 19 dez. 2018.

IPCC. Intergovernmental Panel on climate change. Climate Change 2014: Synthesis Report. Contribution of Working Groups I, II and III to the Fifth Assessment Report of the Intergovernmental Panel on Climate Change [Core Writing Team, R.K. Pachauri and L.A. Meyer (eds.)]. IPCC, Geneva, Switzerland, p. 151. 2014.

JACOX, M. G.; HAZEN, E. L.; ZABA, K. D.; EUDNICK, D. L.; EDWARDS, A. M. et al. Impacts of the 2015-2016 El Niño on the California Current System: Early assessment and comparison to past events. Geophysical Research Letters, v. 43, n. $13, \quad$ p. 7072-7080, jul. 2016. Disponível em: https://doi.org/10.1002/2016GL069716. DOI: 10.1002/2016GL069716. Acesso em 21 dez. 2018.

KIM, W.; YEH, S. W.; KIM, J. H.; KUG, J. S.; KWON, M. The unique 2009-2010 EI Niño event: A fast phase transition of warm pool El Niño to La Niña. Geophysical Research Letters, v. 38, n. 15, ago. 2011. Disponível em: https://doi.org/10.1029/2011GL048521. doi: 10.1029/2011GL048521. Acesso em 20 dez. 2018.

LEVINE, A. F. Z.; McPHADEN, M. J. How the July 2014 easterly wind burst gave the 2015-2016 El Niño a head start. Geophysical Research Letters, v. 43, n. 12, p. 6503-6510, jun. 2016. Disponível em: https://doi.org/10.1002/2016GL069204. DOI: 10.1002/2016GL069204. Acesso em 20 dez. 2018.

LIMBERGER, L.; SILVA, M. E. S. Precipitação na bacia amazônica e sua associação à variabilidade da temperatura da superfície dos oceanos Pacífico e Atlântico: uma revisão. Geousp - Espaço e Tempo, v. 20, n. 3, p. 657-675, 2016. Disponível em: https://doi.org/10.11606/issn.2179-0892.geousp.2016.105393. DOI: 10.11606/issn.2179-0892.geousp.2016.105393. Acesso em 22 dez. 2018.

LOPES, M. N. G.; SOUZA, E. B.; FERREIRA, D. B. S. Climatologia regional da precipitação no estado do Pará. Revista Brasileira de Climatologia, Curitiba, v. 12, n. 1, 2013. Disponível em: http://dx.doi.org/10.5380/abclima.v12i1.31402. DOI: 10.5380/abclima. v12i1.31402. Acesso em 23 dez. 2018. 
MARENGO, J. A.; ALVES, L. M.; BESERRA, E. A.; LACERDA, F. F. Variabilidade e mudanças climáticas no semiárido brasileiro. In: INSA (Org.). Recursos hídricos em regiões áridas e semiáridas. Campina Grande: Instituto Nacional do Semiárido, 2011 , p. 384-422. Disponível em: https://portal.insa.gov.br/images/acervolivros/Recursos\%20H\%C3\%ADdricos\%20e

m\%20Regi\%C3\%B5es\%20Semi\%C3\%A1 ridas\%20estudos\%20e\%20aplica\%C3\%A 7\%C3\%B5es.pdf. Acesso em 22 dez. 2018.

MEUSBURGER, K.; STEEL, A.; PANAGOS, P.; MONTANARELLA, L.; ALEWELL, C.. Spatial and temporal variability of rainfall erosivity factor for Switzerland. Hydrology and Earth System Science, v. 16, p. 167-177, 2012. Disponível em: 10.5194/hess-16-167-2012. DOI: 10.5194/hess-16-167-2012. Acesso em 06 fev. 2018.

NASCIMENTO, T. S.; SARAIVA, J. M. B; SENAA, R; AGUIAR, F. E. O. Preenchimento de falhas em banco de dados pluviométricos com base em dados do CPC (Climate Prediction Center): Estudo de caso do rio Solimões-Amazonas. Revista Brasileira de Climatologia, Curitiba, v. 7, p. 143-158, set. 2009. Disponível em: http://dx.doi.org/10.5380/abclima.v7i0.25643. DOI: 10.5380/abclima.v7i0.25643. Acesso em 18 dez. 2018.

PAULA, G. M. STRECK, N. A.; ALENCAR JUNIOR, Z.; ELITZ, F. L. F.; HELDWEN, B. A.et al. Influência do fenômeno El Niño na erosividade das chuvas na região de Santa Maria (RS). Revista Brasileira de Ciência do Solo, Viçosa, v. 34, n. 4, p. 1315-1324, jul./ago. 2010. Disponível em: http://dx.doi.org/10.1590/S010006832010000400028. DOI: 10.1590/S0100-06832010000400028. Acesso em 22 dez. 2018.

PINTO, A.; AMARAL, P.; SOUZA JUNIOR, C.; VERÍSSIMO, A.; SALOMAO, R. et al. Diagnóstico socioeconômico e florestal do município de Paragominas. Belém: Imazon, 2009. socioeconomico-e-florestal-do.pdf. Acesso em 19 dez. 2018.

PRODANOV, C. C.; FREITAS, E. C. Metodologia do Trabalho Científico: Métodos e Técnicas da Pesquisa e do Trabalho Acadêmico. 2 ed. Novo Hamburgo: Feevale, 2013. Disponível em: http://www.feevale.br/Comum/midias/8807f05a-14d0-4d5bb1ad-1538f3aef538/E-book\%20Metodologia\%20do\%20Trabalho\%20Cientifico.pdf. Acesso em 19 dez. 2018.

REBOITA, M. S.; SANTOS, I. A. Influência de alguns padrões de teleconexão na precipitação no Norte e Nordeste do Brasil. Revista Brasileira de Climatologia, ano 10 , v. 15, p. 28-48, jul./dez. 2014. Disponível em: http://dx.doi.org/10.5380/abclima.v15i0.37686. doi: 10.5380/abclima.v15i0.37686. Acesso em 21 dez. 2018.

SAKAMOTO, C. K.; SILVEIRA, I. O. Como fazer projetos e Iniciação Científica. São Paulo: Paulus, 2014.

SILVA, V. P. R.; PEREIRA, E. R. R.; AZEVEDO, P. V.; SOUSA, F. A. S.; SOUSA, I. F. Análise da pluviometria e dias chuvosos na região Nordeste do Brasil. Revista ENCICLOPÉDIA BIOSFERA, Centro Científico Conhecer - Goiânia, v.16 n.29; p. 1729 
Brasileira de Engenharia Agrícola e Ambiental, Campina Grande, v. 15, n. 2, p. 131-138, 2011. Disponível em: http://dx.doi.org/10.1590/S141543662011000200004. DOI: 10.1590/S1415-43662011000200004. Acesso em 23 dez. 2018.

SILVA, V. P. R.; PEREIRA, E. R. R; ALMEIDA, R. S. R. Estudo da variabilidade anual e intra-anual da precipitação na Região Nordeste do Brasil. Revista Brasileira de Meteorologia, São José dos Campos, v. 27, n. 3, p. 163-172, 2012. Disponível em: http://dx.doi.org/10.1590/S0102-77862012000200005. DOI: 10.1590/S010277862012000200005. Acesso em 20 dez. 2018.

TORRES, F. T. P; MACHADO, P. J. O. Introdução à climatologia. São Paulo: Cengage Learning, p. 250, 2011. Disponível em: https://issuu.com/cengagebrasil/docs/livreto_9788522111473. Acesso em $23 \mathrm{dez}$. 2018.

WILLEMS, P.; NIELSEN-ARNBJERG, A.; OLSSON, J.; NGUYEN, V. T. V. Climate Change impact assessment on urban rain fall extremes and urban drainage: Methods and shortcomings. Atmosferic Research, v. 103, p. 106-118, jan. 2012. Disponível em: https://doi.org/10.1016/j.atmosres.2011.04.003. DOI: 10.1016/j.atmosres.2011.04.003. Acesso em 06 fev. 2018. 